\title{
Cancer History Unknown
}

National Cancer Institute

\section{Source}

National Cancer Institute. Cancer History Unknown. NCI Thesaurus. Code C160187.

An indication that a cancer history is unknown. 